\title{
New Steroidal Saponins from Rhizomes of Costus spiralis
}

Bernadete P. da Silva and José P. Parente*

Laboratório de Química de Plantas Medicinais, Núcleo de Pesquisas de Produtos Naturais, Universidade Federal do Rio de Janeiro, PO Box 68045, CEP 21944-970 Rio de Janeiro, Brazil. Fax: +55-21-2562-6791. E-mail: parente@nppn.ufrj.br

* Author for correspondence and reprint requests

Z. Naturforsch. 59c, 81-85 (2004); received May 21, 2003

Two new steroidal saponins were isolated from the rhizomes of Costus spiralis Rosc. Their structures were established as (3 $\beta, 25 R)-26-(\beta$-D-glucopyranosyloxy)-22-hydroxyfurost-5en-3-yl $O$-D-apio- $\beta$-D-furanosyl- $(1 \rightarrow 2)-O$-[ $\alpha$-L-rhamnopyranosyl- $(1 \rightarrow 4)]-\beta$-D-glucopyranoside (1) and $(3 \beta, 25 R)$-26-( $\beta$-D-glucopyranosyloxy)-22-hydroxyfurost-5-en-3-yl $O$-D-apio- $\beta$-D-furanosyl-(1 $\rightarrow 4)-O$ - $[\alpha$-L-rhamnopyranosyl- $(1 \rightarrow 2)]-\beta$-D-glucopyranoside $\quad(\mathbf{2}) . \quad$ Their structural identifications were performed using detailed analyses of ${ }^{1} \mathrm{H}$ and ${ }^{13} \mathrm{C}$ NMR spectra including 2D NMR spectroscopic techniques (DEPT, COSY, HETCOR and COLOC) and chemical conversions. The steroidal saponins were evaluated for anti-inflammatory activity.

Key words: Costus spiralis, Steroidal Saponins, Anti-inflammatory Activity

\section{Introduction}

Costus spiralis Rosc. (Costaceae) is used in the Brazilian folk medicine as a diuretic to relieve complaints of the bladder and urethra and to expel kidney stones (Corrêa, 1984; Cruz, 1965). Pharmacological evaluation of the antiurolithiac activity of the water extract of this plant in rats confirmed the folk information (Viel et al., 1999). Previous phytochemical studies on $C$. spiralis have revealed the occurrence of sterols and furostanol glycosides (Willuhn and Pretzsch, 1985) and flavonol glycosides (Antunes et al., 2000). As part of our program of the chemical investigation of bioactive steroidal saponins, we have now examined the rhizomes of this plant. We isolated two new steroidal saponins from $C$. spiralis, along with evaluations of their anti-inflammatory properties.

\section{Materials and Methods}

\section{Plant material}

Fresh rhizomes of Costus spiralis were obtained from the Ornamental Plant Garden of Federal University of Rio de Janeiro, in September 2000 and a voucher specimen is maintained in the Laboratory of Chemistry of Medicinal Plants.

\section{General procedures}

Melting points were determined by an Electrothermal 9200 micro-melting point and are uncor- rected. Optical rotations were measured on a Perkin Elmer 243B polarimeter. IR spectra were measured on a Perkin Elmer 599B, negative LSIMS carried out using thioglycerol as the matrix and $\mathrm{Cs}$ ions accelerated at $35 \mathrm{kV}$ (acceleration voltage: $8 \mathrm{kV}$ ). Mass spectra and GC-MS were taken on a VG Auto SpecQ spectrometer and a Shimadzu GCMS-QP5050A gas chromatograph mass spectrometer, respectively. GC was carried out with FID, using a glass capillary column (0.25 m× $25 \mathrm{~m}, 0.25$ micron, J. W. Scientific Inc.) DB-1. NMR spectra were measured in $\mathrm{C}_{5} \mathrm{D}_{5} \mathrm{~N}$ (100 $\mathrm{mg}$ of steroidal saponin in $0.5 \mathrm{ml}$ ) at $25^{\circ} \mathrm{C}$ with a Varian Gemini 200 NMR spectrometer, with tetramethylsilane $(\delta=0.00)$ used as internal standard. ${ }^{1} \mathrm{H}$ NMR spectra were recorded at $200 \mathrm{MHz}$ and ${ }^{13} \mathrm{C}$ NMR spectra at $50 \mathrm{MHz}$. Silica gel columns (230-400 mesh ASTM, Merck) and Sephadex LH-20 (Pharmacia) were used for CC. TLC was performed on silica gel plates (Kieselgel $60 \mathrm{~F}_{254}$, Merck) using the following solvent systems: (A) $\mathrm{CHCl}_{3} / \mathrm{MeOH} / \mathrm{H}_{2} \mathrm{O} \quad(65: 35: 10 \mathrm{v} / \mathrm{v} / \mathrm{v}$, lower phase) for steroidal saponins $\mathbf{1}$ and 2, (B) $\mathrm{CHCl}_{3} / \mathrm{MeOH}(12: 1 \mathrm{v} / \mathrm{v})$ for pseudosapogenin and (C) $n$ - $\mathrm{BuOH} / \mathrm{Me}_{2} \mathrm{CO} / \mathrm{MeOH} \quad(4: 5: 1 \mathrm{v} / \mathrm{v} / \mathrm{v})$ for monosaccharides. Spray reagents were orcinol/ $\mathrm{H}_{2} \mathrm{SO}_{4}$ for steroidal saponins $\mathbf{1}$ and $\mathbf{2}$ and monosaccharides and $\mathrm{CeSO}_{4}$ for pseudosapogenin. 


\section{Extraction and isolation}

Fresh rhizomes $(1 \mathrm{~kg})$ were extracted with $80 \%$ aqueous $\mathrm{MeOH}$ (3 l) for $72 \mathrm{~h}$ at room temperature. The extract was concentrated under reduced pressure to remove most of the $\mathrm{MeOH}$ and the resulting aqueous phase was shaken with $n$-BuOH [water/n-BuOH (1:1 v/v)]. This procedure was repeated and the resulting organic phase was evaporated in vacuo, the residue dissolved in $\mathrm{MeOH}$, precipitated by $\mathrm{Et}_{2} \mathrm{O}$ addition, and washed with $\mathrm{Et}_{2} \mathrm{O}$ to give a crude material $(3.8 \mathrm{~g})$. The residue was dissolved in $\mathrm{MeOH}$ and roughly chromatographed on Sephadex LH-20 with MeOH. The fractions were combined based on the TLC profiles to give the saponin mixture $(1.3 \mathrm{~g})$. Further purification by chromatography on a silica gel column provided several fractions which two TLC homogeneous compounds 1 (270 $\left.\mathrm{mg}, R_{\mathrm{f}} 0.52\right)$ and 2 (153 mg, $\left.R_{\mathrm{f}} 0.55\right)$ which gave dark green colors with orcinol $/ \mathrm{H}_{2} \mathrm{SO}_{4}$.

\section{Compound 1}

Colorless needles. $-[\alpha]_{\mathrm{D}}^{25}-106^{\circ}(c 0.1, \mathrm{MeOH})$. M.p. $216-218{ }^{\circ} \mathrm{C}$. $-\mathrm{IR}(\mathrm{KBr}): v_{\max }=3430(\mathrm{OH})$, $1050(\mathrm{C}-\mathrm{O}), 913,838,813,638 \mathrm{~cm}^{-1}$ [(25R)-furostanol, intensity $913<838$ ]. - Negative LSIMS: $m / z=$ $1033[\mathrm{M}-\mathrm{H}]^{-} .-{ }^{1} \mathrm{H}$ and ${ }^{13} \mathrm{C}$ NMR data: Tables I and II.

\section{Compound 2}

Colorless needles. $-[\alpha]_{\mathrm{D}}^{25}-110^{\circ}(c 0.1, \mathrm{MeOH})$. M.p. $218-220^{\circ} \mathrm{C}$. $-\mathrm{IR}(\mathrm{KBr}): v_{\max }=3430(\mathrm{OH})$, 1050 (C-O), 913, 838, 813, $638 \mathrm{~cm}^{-1}$ [(25R)-furostanol, intensity $913<838$ ]. - Negative LSIMS: $m / z=$ $1033[\mathrm{M}-\mathrm{H}]^{-} .-{ }^{1} \mathrm{H}$ and ${ }^{13} \mathrm{C}$ NMR data: Tables I and II.

\section{Acid hydrolysis of $\mathbf{1}$ and $\mathbf{2}$}

A solution of each compound $(100 \mathrm{mg})$ in $1 \mathrm{M}$ $\mathrm{HCl} / 1$,4-dioxan $(1: 1 \mathrm{v} / \mathrm{v} ; 10 \mathrm{ml})$ was heated in a sealed tube for $1 \mathrm{~h}$ at $100^{\circ} \mathrm{C}$. After cooling, the reaction mixture was neutralized with $3 \% \mathrm{KOH}$ in $\mathrm{MeOH}$ and evaporated to dryness. The salts that deposited on addition of $\mathrm{MeOH}$ were filtered off and the filtrate was passed through a Sephadex LH-20 with $\mathrm{MeOH}$ to give the hydrolysate (93 mg) which was chromatographed on silica gel $\mathrm{CC}$ with $\mathrm{CHCl}_{3} / \mathrm{MeOH} / \mathrm{H}_{2} \mathrm{O}$ (7:3:0.2) to yield the diosgenin $(30 \mathrm{mg})$ and a sugar mixture. Identity of diosgenin was established by comparison with an authentic sample through m.p., IR, ${ }^{1} \mathrm{H}$ and ${ }^{13} \mathrm{C}$ NMR and EIMS. The sugar mixture was dissolved in pyridine and analyzed by silica gel-TLC in the above described solvent system. After spraying, apiose gave a weak yellow spot at $R_{\mathrm{f}} 0.78$, rhamnose gave a green spot at $R_{\mathrm{f}} 0.75$ and glucose gave a blue spot at $R_{\mathrm{f}} 0.70$.

\section{Molar carbohydrate composition and D,L configu- rations}

The molar carbohydrate composition of $\mathbf{1}$ and 2 were determined by GC-MS analyses of their monosaccharides as their trimethylsilylated methylglycosides obtained after methanolysis $(0.5 \mathrm{M}$ $\mathrm{HCl}$ in $\mathrm{MeOH}, 24 \mathrm{~h}, 80^{\circ} \mathrm{C}$ ) and trimethylsilylation (Kamerling et al., 1975). The configurations of the glycosides were established by capillary GC of their trimethylsilylated (-)-2-butylglycosides (Gerwig et al., 1978).

\section{Methylation analysis}

Compounds $\mathbf{1}$ and $\mathbf{2}$ were methylated with DMSO/lithium methylsulfinyl carbanion/ $\mathrm{CH}_{3} \mathrm{I}$ (Parente et al., 1985). The methyl ethers were obtained after hydrolysis ( $4 \mathrm{~N}$ TFA, $\left.2 \mathrm{~h}, 100^{\circ} \mathrm{C}\right)$ and analyzed as partially alditol acetates by GC-MS (Sawardeker et al., 1965).

\section{Animals}

Male BALB/c mice, weighing 15-20 g, were used. The animals were housed under standard environmental conditions and fed with standard rodent diet and water ad libitum.

\section{Anti-inflammatory activity}

Anti-inflammatory activity was evaluated by measuring acetic acid-induced vascular permeability (Whittle, 1964). Male mice (BALB/c, 15-20 g) in groups of five were dosed orally with compounds 1 and $2(100 \mu \mathrm{g} / \mathrm{g}$ body weight $)$ and a positive control, indomethacin $(10 \mu \mathrm{g} / \mathrm{g}$ body weight). After injection of the dye, $0.1 \mathrm{~N}$ acetic acid $(10 \mu \mathrm{l} /$ $\mathrm{g}$ body weight) was injected intraperitoneally. Twenty minutes later, the mice were killed with an overdose of ether and the viscera were exposed after a $1 \mathrm{~min}$ period to allow blood to drain away from the abdominal wall. The animal was held by a flap of the abdominal wall and the viscera were irrigated with $10 \mathrm{ml}$ of saline over a petri dish. The washing was filtered through glass wool and transferred to a 
Table I. Selected ${ }^{1} \mathrm{H}$ NMR assignments ( $\left.\delta(\mathrm{ppm}), J[\mathrm{~Hz}]\right)$ of compounds $\mathbf{1}$ and $\mathbf{2}$ in $\mathrm{C}_{5} \mathrm{D}_{5} \mathrm{~N}^{\mathrm{a}}$.

\begin{tabular}{lccc}
\hline Position & \multicolumn{1}{c}{$\mathbf{1}$} & \multicolumn{1}{c}{$\mathbf{2}$} & ${ }^{1} \mathrm{H}^{-}{ }^{1} \mathrm{H}-\mathrm{COSY}$ \\
\hline \multicolumn{4}{c}{ Aglycone characteristic proton signals } \\
$\mathrm{H}-6$ & $5.30 \mathrm{br}$ s & $5.30 \mathrm{br} \mathrm{s}$ & $\mathrm{H}-7$ \\
Me-18 & $0.85 \mathrm{~s}$ & $0.85 \mathrm{~s}$ \\
Me-19 & $1.10 \mathrm{~s}$ & $1.10 \mathrm{~s}$ \\
Me-21 & $1.22 \mathrm{~d}(6.8)$ & $1.22 \mathrm{~d}(6.8)$ & $\mathrm{H}-20$ \\
Me-27 & $0.98 \mathrm{~d}(6.6)$ & $0.98 \mathrm{~d}(6.6)$ & $\mathrm{H}-25$ \\
\multicolumn{5}{c}{ Sugar methyl group and anomeric protons } \\
Rha-Me & $1.78 \mathrm{~d}(6.3)$ & $1.76 \mathrm{~d}(6.3)$ & Rha-H-5 \\
iGlc-H-1 & $4.98 \mathrm{~d}(7.7)$ & $4.96 \mathrm{~d}(7.7)$ & iGlc-H-2 \\
tGlc-H-1 & $4.82 \mathrm{~d}(7.8)$ & $4.84 \mathrm{~d}(7.8)$ & tGlc-H-2 \\
Rha-H-1 & $6.30 \mathrm{br} \mathrm{s}$ & $5.80 \mathrm{br} \mathrm{s}$ & Rha-H-2 \\
Api-H-1 & $5.95 \mathrm{~d}(3.5)$ & $5.90 \mathrm{~d}(3.5)$ & Api-H-2 \\
\hline
\end{tabular}

a The following conventions were used: iGlc $=$ inner glucose, tGlc $=$ terminal glucose.

test tube. To each tube was added $100 \mu \mathrm{l}$ of $1 \mathrm{~N}$ $\mathrm{NaOH}$ in order to clear any turbidity due to protein, and the absorbance was read at $590 \mathrm{~nm}$.

\section{Results and Discussion}

The fresh rhizomes of $C$. spiralis were extracted with methanol. After concentration under reduced pressure, the methanol extract was partitioned between water and $n$-butanol. Chromatographic separations of the organic phase on Sephadex LH20 and silica gel gave compounds $\mathbf{1}$ and $\mathbf{2}$ which were detected with orcinol/ $\mathrm{H}_{2} \mathrm{SO}_{4}$ reagent. Compounds $\mathbf{1}$ and $\mathbf{2}$ were obtained as colorless needles and gave positive Liebermann-Burchard test for steroidal saponins. The LSIMS showed an ion peak $[\mathrm{M}-\mathrm{H}]^{-}$at $\mathrm{m} / \mathrm{z} 1033$ which, together with ${ }^{13} \mathrm{C}$ NMR spectral data (Table II), suggested the molecular formula as $\mathrm{C}_{50} \mathrm{H}_{82} \mathrm{O}_{22}$ for compounds $\mathbf{1}$ and 2.

In addition to this, the furostanol glycosidic nature of 1 and $\mathbf{2}$ was indicated by the strong absorption bands at $3430 \mathrm{~cm}^{-1}$ for the hydroxyl group and a $25 R$-furostan steroidal structure $(813,838$ and $913 \mathrm{~cm}^{-1}$, intensity $913<838 \mathrm{~cm}^{-1}$ ) in the IR spectrum (Wall et al., 1952), confirmed by ${ }^{1} \mathrm{H}$ and ${ }^{13} \mathrm{C}$ NMR spectra (Tables I and II) (Agrawal et al., 1985; Shao et al., 1997). The ${ }^{1} \mathrm{H}$ NMR spectral data (Table I) of compounds $\mathbf{1}$ and $\mathbf{2}$ contained a signal for the olefinic proton at $\delta 5.30$ (br s, H-6), two secondary methyl protons at $\delta 1.22(\mathrm{~d}, J=6.8 \mathrm{~Hz}$, $3 \mathrm{H}-21)$ and $0.98(\mathrm{~d}, J=6.6 \mathrm{~Hz}, 3 \mathrm{H}-27)$ and two angular methyl protons at $\delta 1.10(\mathrm{~s}, 3 \mathrm{H}-19)$ and 0.85 (s, 3H-18). In addition to this, the COLOC

\begin{tabular}{|c|c|c|c|c|c|c|c|}
\hline $\mathrm{C}$ & 1 & $\mathrm{C}$ & 1 & $\mathrm{C}$ & 2 & $\mathrm{C}$ & 2 \\
\hline 1 & 37.2 & iGlc 1 & 100.1 & 1 & 37.1 & iGlc 1 & 100.0 \\
\hline 2 & 29.7 & 2 & 77.8 & 2 & 29.5 & 2 & 77.8 \\
\hline 3 & 77.9 & 3 & 78.1 & 3 & 77.9 & 3 & 78.0 \\
\hline 4 & 38.5 & 4 & 78.8 & 4 & 38.5 & 4 & 78.8 \\
\hline 5 & 140.3 & 5 & 76.9 & 5 & 140.3 & 5 & 76.7 \\
\hline 6 & 121.5 & 6 & 61.2 & 6 & 121.4 & 6 & 61.2 \\
\hline 7 & 32.2 & tGlc 1 & 104.5 & 7 & 32.2 & tGlc 1 & 104.7 \\
\hline 8 & 31.2 & 2 & 74.8 & 8 & 31.3 & 2 & 74.7 \\
\hline 9 & 50.2 & 3 & 78.1 & 9 & 49.9 & 3 & 78.1 \\
\hline 10 & 36.9 & 4 & 71.8 & 10 & 36.7 & 4 & 71.9 \\
\hline 11 & 20.9 & 5 & 78.8 & 11 & 20.7 & 5 & 78.7 \\
\hline 12 & 39.6 & 6 & 62.7 & 12 & 39.5 & 6 & 62.3 \\
\hline 13 & 40.7 & Rha 1 & 102.7 & 13 & 40.5 & Rha 1 & 101.8 \\
\hline 14 & 56.5 & 2 & 72.3 & 14 & 56.3 & 2 & 72.2 \\
\hline 15 & 31.9 & 3 & 72.2 & 15 & 31.7 & 3 & 72.3 \\
\hline 16 & 80.9 & 4 & 73.7 & 16 & 80.7 & 4 & 73.7 \\
\hline 17 & 63.7 & 5 & 69.3 & 17 & 63.5 & 5 & 69.3 \\
\hline 18 & 16.3 & 6 & 18.2 & 18 & 16.2 & 6 & 18.2 \\
\hline 19 & 18.5 & Api 1 & 110.5 & 19 & 18.3 & Api 1 & 110.7 \\
\hline 20 & 40.5 & 2 & 77.3 & 20 & 40.3 & 2 & 77.2 \\
\hline 21 & 16.5 & 3 & 79.9 & 21 & 16.3 & 3 & 79.6 \\
\hline 22 & 110.7 & 4 & 74.8 & 22 & 110.5 & 4 & 74.8 \\
\hline 23 & 30.3 & 5 & 64.3 & 23 & 30.1 & 5 & 64.2 \\
\hline 24 & 27.9 & & & 24 & 27.7 & & \\
\hline 25 & 33.9 & & & 25 & 33.7 & & \\
\hline 26 & 74.9 & & & 26 & 74.7 & & \\
\hline 27 & 16.9 & & & 27 & 16.7 & & \\
\hline
\end{tabular}

Table II. ${ }^{13} \mathrm{C}$ NMR data of the aglycone and carbohydrate moieties of compounds 1 and 2 in $\mathrm{C}_{5} \mathrm{D}_{5} \mathrm{~N}^{\mathrm{a}}$.

The assignments were made on the basis of DEPT, HETCOR and COLOC experiments. 
spectrum displayed long range couplings between $\mathrm{H}-1$ of the terminal glucose and C-26 of the aglycone. The above ${ }^{1} \mathrm{H}$ NMR spectral data and a comparison of the ${ }^{13} \mathrm{C}$ NMR signals of the aglycone moiety of $\mathbf{1}$ and $\mathbf{2}$ (Table II) with those described in the literature (Agrawal et al., 1985; Shao et al., 1997) showed the structure of the aglycone to be (3 $\beta, 25 R)$-22-hydroxyfurost-5-ene-3,22,26-triol.

In the ${ }^{13} \mathrm{C}$ NMR spectrum of $\mathbf{1}$ and 2 , a $2,4-$ linked inner $\beta$-D-glucopyranosyl unit, a terminal $\beta$ D-glucopyranosyl unit, a terminal $\alpha$-L-rhamnopyranosyl unit and a terminal $\beta$-D-apiofuranosyl unit were clearly observed. The COLOC spectrum of compound $\mathbf{1}$ displayed long range couplings between inner glucose-H-1 at $\delta 4.98$ and aglycone$\mathrm{C}-3$ at $\delta 77.9$, between terminal glucose-H-1 at $\delta 4.82$ and aglycone-C-26 at $\delta 74.9$, between apiose-H-1 at $\delta 5.95$ and inner glucose-C-2 at $\delta 77.8$, and between rhamnose-H-1 at $\delta 6.30$ and inner glucose-C-4 at $\delta 78.8$, indicating that the apiose and rhamnose were linked to the C-2 and $\mathrm{C}-4$ of the inner glucose, respectively. The COLOC spectrum of compound $\mathbf{2}$ displayed long range couplings between inner glucose-H-1 at $\delta 4.96$ and aglycone-C-3 at $\delta 77.9$, between terminal glucose-H-1 at $\delta 4.84$ and aglycone-C-26 at $\delta$ 74.7, between apiose-H-1 at $\delta 5.90$ and inner glucose-C-4 at $\delta 78.8$, and between rhamnose-H-1 at $\delta 5.80$ and inner glucose-C-2 at $\delta 77.8$, indicating that the apiose and rhamnose were linked to the
C-4 and C-2 of the inner glucose, respectively. The signal at $\delta 1.78$ and 1.76 were due to the methyl group of rhamnose of $\mathbf{1}$ and $\mathbf{2}$, respectively. The methylation analyses (Parente et al., 1985) showed a terminal glucopyranose, a terminal apiofuranose, a terminal rhamnopyranose and a 2,4-linked glucopyranose for $\mathbf{1}$ and $\mathbf{2}$.

On acid hydrolysis, compounds $\mathbf{1}$ and $\mathbf{2}$ gave a pseudosapogenin, glucose, rhamnose and apiose. The pseudosapogenin was identified as diosgenin by direct comparison of TLC, m.p., IR, ${ }^{1} \mathrm{H}$ and ${ }^{13} \mathrm{C}$ NMR and EIMS with an authentic sample. The molar carbohydrate composition of $\mathbf{1}$ and $\mathbf{2}$ indicated the presence of four neutral monosaccharides: glucose/rhamnose/apiose (2.0:0.9:0.9; the molar responses of rhamnose and apiose are taken as 1.0) (Kamerling et al., 1975). Their absolute configurations were determined by GC of their trimethylsilylated (-)-2-butylglycosides (Gerwig et al., 1978). D-glucose, L-rhamnose and $\mathrm{D}$-apiose were detected. Consequently, on the basis of IR, ${ }^{1} \mathrm{H}$ and ${ }^{13} \mathrm{C}$ NMR spectroscopy, LSIMS and chemical reactions, the structures of the steroidal saponins 1 and 2 were established as $(3 \beta, 25 R)-26-(\beta$-Dglucopyranosyloxy)-22-hydroxyfurost-5-en-3-yl $O$ D-apio- $\beta$-D-furanosyl- $(1 \rightarrow 2)-O$ - $[\alpha$-L-rhamnopyranosyl- $(1 \rightarrow 4)]-\beta$-D-glucopyranoside and $(3 \beta, 25 R)$ 26-( $\beta$-D-glucopyranosyloxy)-22-hydroxyfurost-5-en3 -yl $O$-D-apio- $\beta$-D-furanosyl- $(1 \rightarrow 4)-O$ - $[\alpha$-L-rham-

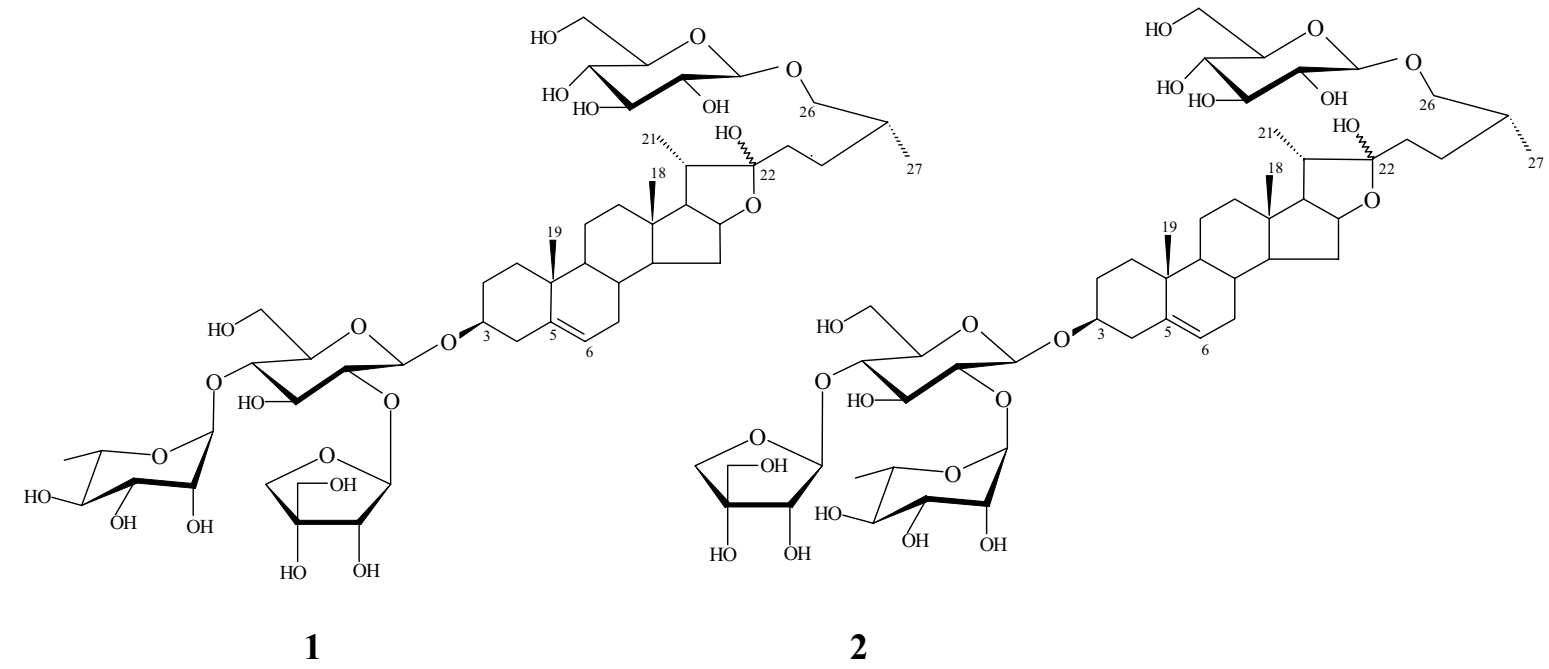

Fig. 1. (3 $\beta, 25 R)$-26( $\beta$-D-glucopyranosyloxy)-22-hydroxyfurost-5-en-3-yl $O$-D-apio- $\beta$-D-furanosyl-( $1 \rightarrow 2)-O$ - $[\alpha$-L-rhamnopyranosyl- $(1 \rightarrow 4)-\beta$-D-glucopyranoside $(1)$ and $(3 \beta, 25 R)-26(\beta$-D-glucopyranosyloxy)-22-hydroxyfurost-5-en-3-yl $O$ D-apio- $\beta$-D-furanosyl- $(1 \rightarrow 4)$ - $O$ - $[\alpha$-L-rhamnopyranosyl- $(1 \rightarrow 2)-\beta$-D-glucopyranoside $(\mathbf{2})$. 
nopyranosyl-(1 $\rightarrow 2)]$ - $\beta$-D-glucopyranoside, respectively (Fig. 1).

In order to confirm popular informations about the use of this plant against inflammatory conditions and based on literature reports of antiinflammatory activities of steroidal saponins (Lacaille-Dubois and Wagner, 1996), this pharmacological property was evaluated for compounds $\mathbf{1}$ and $\mathbf{2}$ using the capillary permeability assay (Whittle, 1964). In the regular dose of $100 \mathrm{mg} / \mathrm{kg}$, compounds $\mathbf{1}$ and $\mathbf{2}$ showed inhibition of the increase in vascular permeability (Fig. 2) caused by acetic acid, which is a typical model of first stage inflammatory reaction. This result suggests that the steroidal saponins $\mathbf{1}$ and $\mathbf{2}$ may be the potential therapeutic agents involved in inflammatory disorders justifying the use of $C$. spiralis in Brazilian traditional medicine.

\section{Acknowledgements}

This work was financially supported by $\mathrm{CNPq}$, FAPERJ and FUJB.

Agrawal P. K., Jain D. C., Gupta R. K., and Thakur R. S. (1985), Carbon-13 NMR spectroscopy of steroidal sapogenins and steroidal saponins. Phytochemistry 24, $2479-2496$

Antunes A. S., da Silva B. P., and Parente J. P. (2000), Flavonol glycosides from Costus spiralis. Fitoterapia 71, 507-510.

Corrêa P. M. (1984), Dicionário das plantas úteis do Brasil e das exóticas cultiváveis. Imprensa Nacional do Instituto Brasileiro de Desenvolvimento Florestal, Rio de Janeiro.

Cruz G. L. (1965), Livro verde das plantas medicinais e industriais do Brasil. Velloso S. A., Belo Horizonte.

Gerwig G. J., Kamerling J. P., and Vliegenthart J. F. G. (1978), Determination of the $\mathrm{D}$ and L configuration of neutral monosaccharides by high-resolution capillary G. L. C. Carbohydr. Res. 62, 349-357.

Kamerling J. P., Gerwig G. J., Vliegenthart J. F. G., and Clamp J. R. (1975), Characterization by gas-liquid chromatography-mass spectrometry and proton-magnetic-resonance spectroscopy of pertrimethylsilyl glycosides obtained in methanolysis of glycoproteins and glycopeptides. Biochem. J. 151, 491-495.

Lacaille-Dubois M. A. and Wagner H. (1996), A review of the biological and pharmacological activities of saponins. Phytomedicine 2, 363-386.

Parente J. P., Cardon P., Leroy Y., Montreuil J., Fournet B., and Ricart G. (1985), A convenient method for

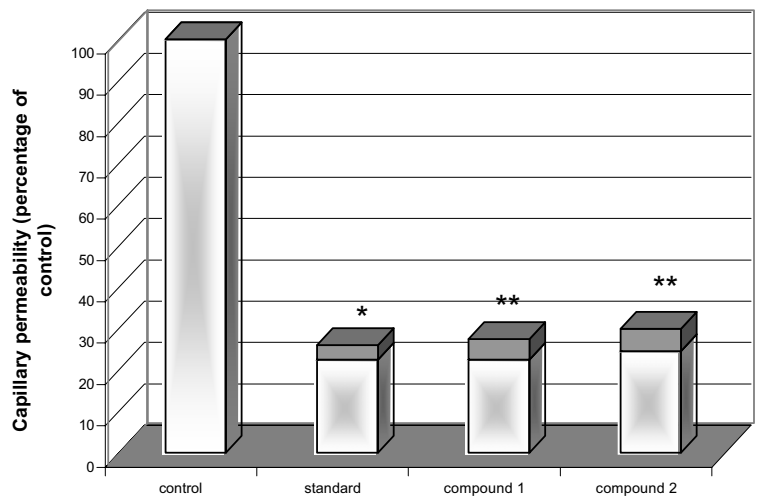

Fig. 2. Effect of compounds $\mathbf{1}$ and $\mathbf{2}(100 \mathrm{mg} / \mathrm{kg}$, p.o.) on acetic acid-induced vaular permeability in mice. Standard: indomethacin $(10 \mathrm{mg} / \mathrm{kg}$, p.o. $)$. Results are mean $+/-$ S.E.M. $(n: 5) ; * p<0.05, * * \mathrm{p}<0.01 v s$. control; Student's $t$-test. methylation of glycoprotein glycans in small amounts by using lithium methylsulfinyl carbanion. Carbohydr. Res. 141, 41-47.

Sawardeker J. S., Sloneker J. H., and Jeanes, A. (1965), Quantitative determination of monosaccharides as their alditol acetates by gas liquid chromatography. Anal. Chem. 37, 1602-1604.

Shao Y., Poobrasert O., Kennelly E. J., Chin C. K., Ho C. T., Huang M. T., Garrison S. A., and Cordell G. A. (1997), Steroidal saponins from Asparagus officinalis and their cytotoxic activity. Planta Med. 63, 258262.

Viel T. A., Domingos C. D., Monteiro A. P. D., LimaLandman M. T. R., Lapa A. J., and Soucar C. (1999), Evaluation of the antiurolithiatic activity of the extract of Costus spiralis Roscoe in rats. J. Ethnopharmacol. 66, 193-198.

Wall M. E., Eddy C. R., McClennan M. L., and Klump M. E. (1952), Detection and estimation of steroidal sapogenins in plant tissue. Anal. Chem. 24, 13371341.

Whittle B. A. (1964), The use of changes in capillary permeability in mice to distinguish between narcotic and nonnarcotic analgesics. Br. J. Pharmacol. Chemother. 22, 246-253.

Willuhn G. and Pretzsch G. (1985), Diosgenin and sterols from Costus spiralis. Planta Med. 3, 185-187. 